\title{
Resources Allocation and Operation Analysis of Sport Equipment
}

\author{
Wang Junbo ${ }^{1, a}$ \\ ${ }^{1}$ Department of Stomatology, Xingtai Medical College,Xingtai,Hebei,054000,China \\ axingtaiyizhuan1@163.com
}

Keywords: sport equipment; resources allocation; operation; model

\begin{abstract}
: this paper is based on theory model of resources allocation-profit and adopts experience choice, Delphi method to construct index and system for efficiency measurement with 2 indexes of I class, 8 indexes of 2 class and 11 indexes of 3 class. On the basis of constructing measurement index system, it applies CCR model of DEA, SE-DEA and Malmquist index model to make measurement on efficiency of resources allocation. It chooses 11 indexes to make regression to analyze the main factors of affecting efficiency change. The test result indicates that allocation structure of the mass sport resources, sport awareness of community resident, mass sport organization have obvious positive effect in increasing allocation efficiency of community sport resources, effect of regional economic level on sport resources allocation is inconsistent to the original assumption.
\end{abstract}

\section{Introduction}

During the 12th Five Year plan period, contradiction between the increasingly diversified sport demand of the public and insufficient social and sport resources is still the main problem in sports development of China, especially it in the field[1,2] of mass. Community sport is regarded as the important organization form for the development of mass sport; the overall condition of sport resources allocation in community will directly affect development level of community sport. At present, the reality demand such as serious insufficiency in total amount of community sport resources allocation, low efficiency and unbalanced structure, which needs to make research on problem of sport resources allocation in community. In recent years, with the rapid development in Chinese economy, people's living standard is gradually increasing, community residents are having urgent demand in increasing health quality, enriching cultural life, promoting cultural and ideological progress, constructing harmonious socialist society, so community sport quietly emerges and is rapidly developing, it has become to be one indispensable part for resident life in community. The activity of bodybuilding by all people, hundred club going into community have been developed in large-scale.

It also makes evaluation research on it, which provides references and decision-making base for sport administrative department to increase resources allocation efficiency of community sport and optimizing allocation structure.

\section{Resources allocating system of community sport}

As it is indicted by diagram 1, the element quantity, quality and its initiative of labor force resources of community sport will affect scale, efficiency and quality of other resources allocation to a larger extent, even it plays an important effect on development level of community sport. The financial element resources of community sport provides fund support in developing community sport activity, public service of community sport and product supply, development degree of community sport, health level of community residents, resources allocation efficiency of community sport are present positive correlation to input degree of financial element resources. The material resources of community sport are the material base to provide public service and product to community sport and meet sport demand of community residents. The information resources of community sport is information support in publicizing bodybuilding method of human resources element, increasing body-building awareness of community residents as well as organizing and 
developing community sport activity. The resources element of community sport organization is the organizer and developer of community sport activity; meanwhile, it is also the producer and supplier of service and product of community sport. Therefore, organizing resources element is the important carrier to promote sport development in community and develop community sport activity.

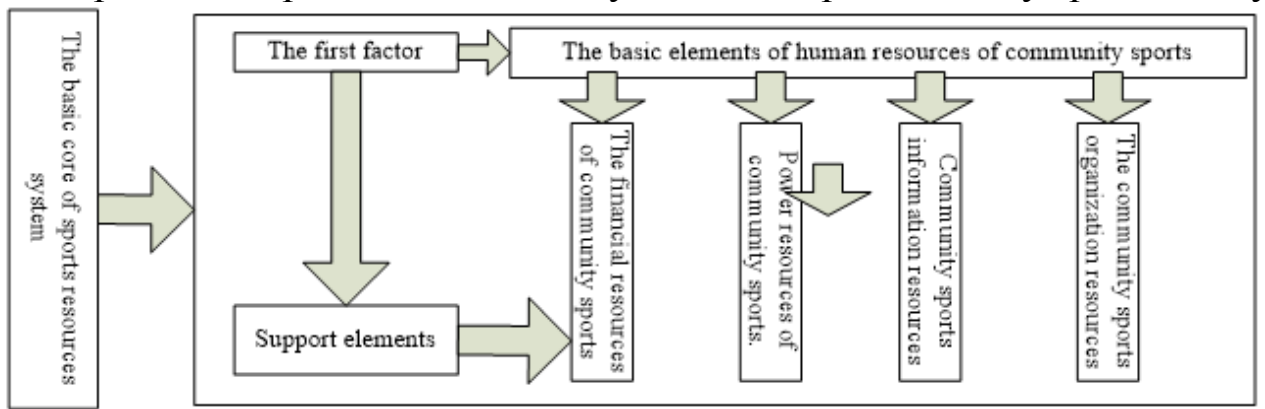

Diagram 1 Subsystem and structure diagram of sport resources in basic and core community

The overall and functional community sport resources element includes 3 kinds of resources elements such as community sport system, market and culture etc. Of which, market resources element of community sport and cultural resources element belong to inductive element community sport resources, system resources element of community sport belongs to compulsory element of community sport resources. The above-mentioned 3 kinds of elements have different classification, but they all belong to system range, just system and market resources element belong to the formal system, culture resources element belongs to the informal system range. Market resources element of community sport and culture resources element have nature of self-organization, while system resources element has design characteristic of national compulsory. It is indicated by diagram 2.

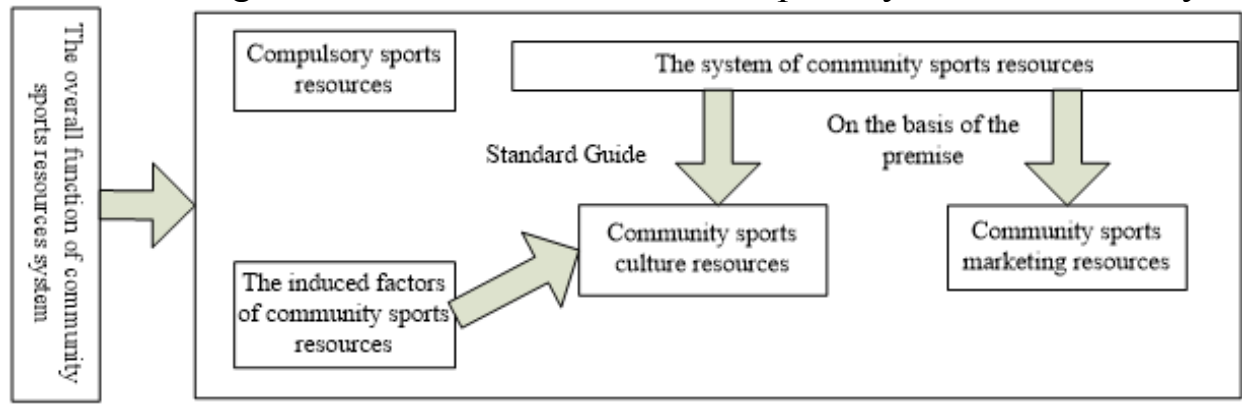

Diagram 2 Subsystem and structure diagram of sport resources element of overall and functional community

\section{Evaluation frame on sport resources allocation system in community}

The research process on resources allocation and efficiency evaluation in community sport include choice of evaluation index, choice on evaluation method, construction of evaluation model etc, whether index choice is reasonable or not, method choice is correct or not, model construction is scientific or nor etc will all affect measurement result on resources allocation efficiency of community sport resources. If we apply result of efficiency measurement into the scientific decision process of community sport resources allocation, different measurement results have different guidance direction on allocation behavior. The correct measurement result is helpful for efficiency in scientific decision-making of community sport resources allocation, while incorrect measurement result will have no help on scientific decision-making of decision maker, on the contrary, it will guide decision maker to produce wrong result in allocation. Therefore, in the process of evaluating resources allocation efficiency of community sport, index system of reasonably designing resources allocation efficiency, choosing correct measurement method and constructing reasonable measurement model will have important meanings to make evaluation as well as rationality and correction of effect element analysis on resources allocation efficiency of community sport. The content structure on resources allocation efficiency evaluation in community sport is indicated by diagram 3. 


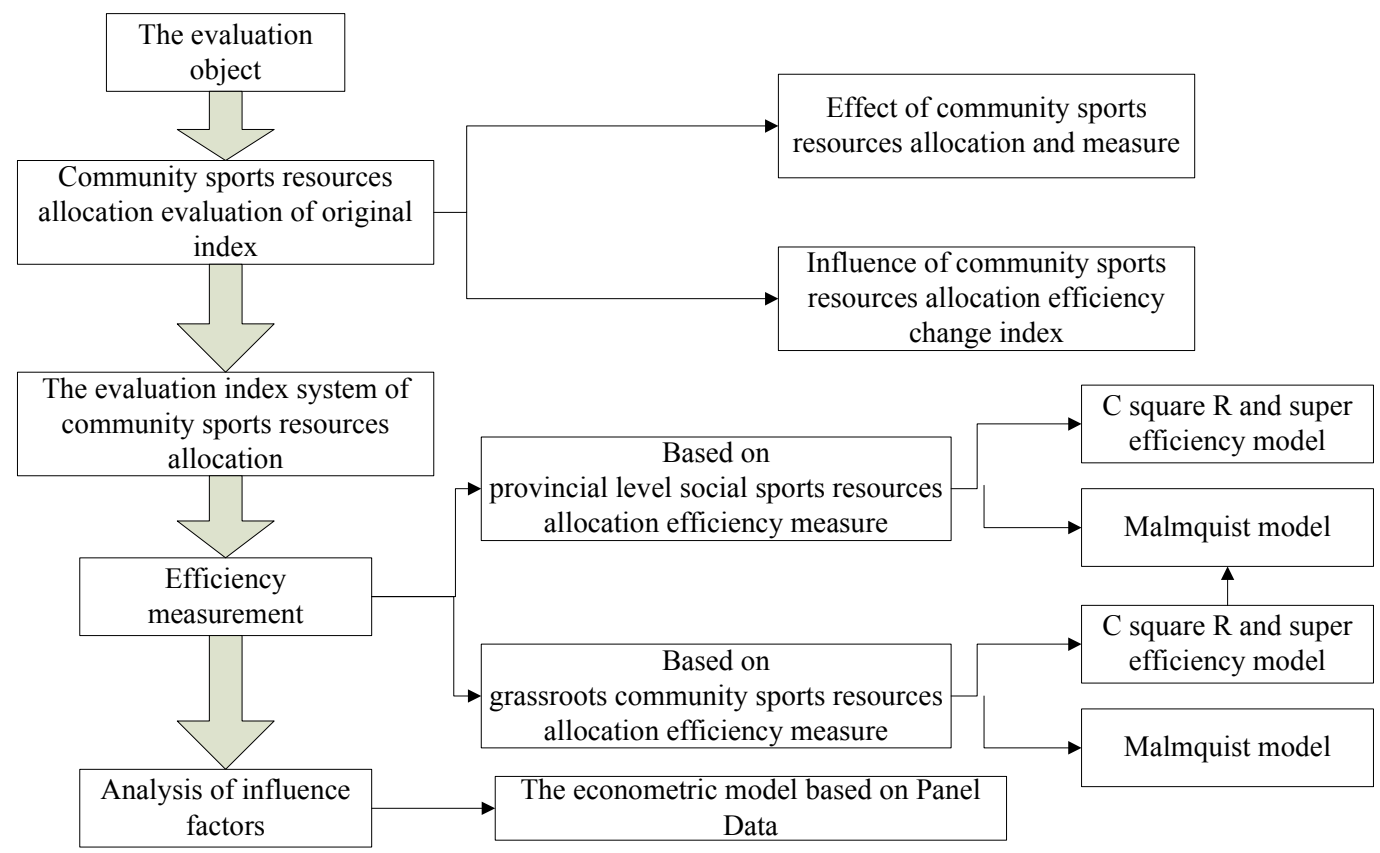

Diagram 3 Evaluation content structure diagram on resources allocation efficiency in community sport

\section{Evaluation index system construction on resources allocation efficiency of community sport}

There are 6 indexes as for input system, they are mainly as follows: human resources element index, material resources element index, finance resources element index, system resources element index, organization resources element index etc. As for input system, every resources element index also includes much more detailed resources element index, human resources element index includes the number of administrators of community sport, the number of instructor of community sport, the fund amount of social input, consumption and expenditure of residents in sport, the number of carder of community sport etc. Finance resources includes fund amount of government input into mass sport career, fund amount into sports lottery input, fund amount of social input, consumption expenditure of resident sport etc. Material resources element index includes place square of public sport, the number of stadium of public sport, the number of project of body-building for all people, the opening condition of sport place in jurisdictions area etc. Information resources element includes propaganda activity for body-building for all people, the number of lecture development of body-building knowledge etc. System resources index includes administration system of community sport, it chooses 20 experts in sport sociology, sport management as well as government staff in charge of mass in sport bureau as investigation objects, it has totally carried out expert questionnaire survey for twice, it makes questionnaire survey by experts for the second time on the basis of questionnaire survey by experts, every index is given mark of 5, 4, 3, 2, 1 according to situation of very important, important, ordinary, unimportant, fairly unimportant. In the process of investigation on the second time, the experts only give choice result; it does not require experts to give correction suggestion. The variation parameter is the ratio of index standard deviation and its weighted average, the smaller of variation parameter, which shows that tendency of expert suggestion, is higher. We generally think the coordination degree of expert suggestion with variation parameter is bigger than 0.25 is inconsistent.

Suppose Xij indicates expert of the $\mathrm{i}$, the $\mathrm{j}$ score, now there are totally $\mathrm{n}$ experts, $\mathrm{m}$ indexes, then :

$$
M_{j}=\frac{1}{n} \sum_{i=1}^{n} X_{i j}
$$




$$
S_{j}=\sqrt{\frac{1}{n-1} \sum_{i=1}^{n}\left(X_{i j}-M_{j}\right)}
$$

Formula of variation parameter is as follows:

$$
V_{j}=\frac{S_{j}}{M_{j}}
$$

$\mathrm{Vj}$. indicates variation parameter of index, $\mathrm{Sj}$ indicates standard deviation of index, $\mathrm{Mj}$ indicates the average of index, the smaller of $\mathrm{Vj}$, the higher coordination degree of expert suggestion in index $\mathrm{j}$.

The coordination parameter $\mathrm{W}$ reflects concentration degree of expert suggestion; its calculation formula has 2 kinds:

(1)When experts have not given the same evaluation:

$$
W=\frac{12 \sum_{j=1} d_{j}^{2}}{m^{2} n\left(n^{2}-1\right)}
$$

(2)When experts give the same evaluation, the denominator of the above formula needs to reduce one correction coefficient, at this time, $\mathrm{Ti}$ is index with the same score. $\mathrm{L}$ is the same score group in $\mathrm{i}$ expert score, $\mathrm{L}=1,2,3 \ldots, \mathrm{L}, \mathrm{t}_{\mathrm{L}}$ is the same score in $\mathrm{L}$ group.

$$
\begin{gathered}
W=\frac{12 \sum_{j=1} d_{j}^{2}}{m^{2} n^{3}-m \sum_{i=1}^{m} T^{i}} \\
T_{i}=\sum_{L=1}^{L}\left(t_{L}^{3}-t_{L}\right)
\end{gathered}
$$

\section{Evaluation method choice and model construction on resources allocation efficiency of community sport}

$\mathrm{C}^{2} \mathrm{R}$ model is proposed by Chames, Copper, Rhodes (1978) and the most usual efficiency measurement model, its basic assumption is that DEA with no change in scale and profit, whose efficiency measurement process with efficiency measurement unit with the same nature is regarded as decision-making unit. Input-DEA model: it is based on the input technology efficiency that is under the certain output, it makes evaluation by using ratio of minimal input and actual input. Or the tendency of decision-maker is reduction in input that is to solve the minimal value of 0 . Output-DEA model: it is based on the output technology efficiency, or under combination of certain input, it makes evaluation by real output and maximum output. Or the tendency of decision-maker is increase in input that is to solve the maximum value of $\mathrm{Z}$.

$\mathrm{C}^{2} \mathrm{R}$ model is as follows:

$$
\begin{aligned}
& \max \frac{u^{T} Y_{0}}{v^{T} X_{0}} \\
& \text { st } \frac{u^{T} Y_{0}}{v^{T} X_{0}} \leq 1, j=1, \ldots, n \\
& u \geq 0, v \geq 0
\end{aligned}
$$

The reality data on resources allocation in community sport contains section data, time sequence data and panel data. It is based on real condition on efficiency measurement of community sport resources allocation, in order to precisely reflect comparison and analysis between many decision-making units and efficiency values of many years, it is necessary to adopt Malmquist index to make measurement on efficiency value of resources allocation. Malmquist index is to measure TFP change of 2 data points by calculating one distance ratio of data point corresponds to one common 
technology. If technology of $t$ is used to be regard as referential technology, so the Malmquist from period $t$ to $S$ is as follows: if change index of TEP is the technology in period $S$ and regarded as referential technology, it can be written as follows:

$$
m_{0}^{s}\left(q_{s}, x_{s}, q_{t}, x_{t}\right)=\frac{d_{0}^{s}\left(q_{t}, x_{t}\right)}{d_{o}^{s}\left(q_{s}, x_{s}\right)}
$$

It makes regression analysis on factors of affecting resources allocation efficiency in community sport, it uses organization number of mass sport and administrators number of community sport as internal factors of affecting resources allocation efficiency of community sport to make regression analysis. The detailed measure factors, detailed index and symbol of affecting resources allocation efficiency are indicated by diagram 1

Table 1 Factors of affecting resources allocation efficiency change in Chinese community sport

\begin{tabular}{|c|c|c|}
\hline Measurement factor & Detailed index & Symbol \\
\hline Consumption level of residents & consumption level of residents & Conlev \\
\hline $\begin{array}{l}\text { Economic development level in } \\
\text { region }\end{array}$ & Per GDP & EcoLev \\
\hline Income level of residents & disposable income of residents in city and town & Inlev \\
\hline Education level & The total expenditure amount of education fund & EduLev \\
\hline Population scale & The total number of population in the end year & Popsize \\
\hline Jurisdiction area & Resident place and building land square & Area \\
\hline Sport awareness & $\begin{array}{c}\text { The number of people usually participate in sport } \\
\text { exercise }\end{array}$ & Spocon \\
\hline $\begin{array}{l}\text { Resources allocation } \\
\text { organization for mass sport }\end{array}$ & Fund expenditure of mass sport & Spoexp \\
\hline $\begin{array}{c}\text { The number of mass sport } \\
\text { organization }\end{array}$ & The number of sport club and organization & Spoass \\
\hline $\begin{array}{l}\text { The number of administrators } \\
\text { of mass sport }\end{array}$ & $\begin{array}{l}\text { The number of community club } \\
\text { The number of administrators of mass } \\
\text { sport(part-time and full-time) }\end{array}$ & $\begin{array}{l}\text { Commclub } \\
\text { Spomang }\end{array}$ \\
\hline
\end{tabular}

\section{Demonstration analysis on resources allocation in community sport}

The base model, firstly, it confirms random effect model and fixed effect model by Hausman test. The Hausman test result indicates that this model can not refuse original assumption on the obvious level of $1 \%$, and the regression result of random effect model has significance with the $F$ value is above $1 \%$. Therefore, it should choose random effect model to make regression analysis. It adopts GLS and applies GEM to make evaluation on panel; the detailed regression result is indicated by the following table:

Table 2 Regression analysis result on affect factors of resources allocation efficiency in community sport

\begin{tabular}{|c|c|c|c|c|c|c|}
\hline \multirow[t]{2}{*}{$\begin{array}{l}\text { independent } \\
\text { variable }\end{array}$} & $\begin{array}{l}\text { Change rate } \\
\text { efficiency }\end{array}$ & f technology & $\begin{array}{l}\text { depend } \\
\text { Advanceme } \\
\text { technology }\end{array}$ & $\begin{array}{l}\text { variable } \\
\text { rate of }\end{array}$ & $\begin{array}{l}\text { Index chang } \\
\text { Malmquist }\end{array}$ & \\
\hline & coefficient & $Z$ value & coefficient & $Z$ value & coefficient & $Z$ value \\
\hline Conlev & -2.1590 & -1.0700 & -2.0489 & -0.9670 & -0.9320 & -0.4520 \\
\hline Ecolev & -0.0049 & 0.0700 & 0.0560 & 0.9040 & 0.0310 & 0.5500 \\
\hline Inlev & 0.2569 & 1.2680 & 0.7140 & 1.2450 & 0.2879 & 1.6700 \\
\hline Edulev & 0.7257 & 1.4630 & 0.2536 & $1.7100 * *$ & 0.2973 & 0.7680 \\
\hline Popsize & 5.6335 & 1.9000 & 2.6431 & 0.9400 & 3.1790 & 1.6400 \\
\hline Area & -0.1730 & -0.4500 & 0.2254 & 1.3300 & 0.3900 & 1.1202 \\
\hline Spocon & 0.1606 & $2.5800^{*}$ & 0.2310 & $1.7200 * *$ & 0.1700 & $2.1500 * *$ \\
\hline Spoxp & 0.0745 & 1.2100 & 0.0016 & 0.6700 & 0.0054 & $0.5600 * *$ \\
\hline
\end{tabular}




$\begin{array}{llccccc}\text { Spoass } & -0.1506 & 2.1305 & -0.6120 & -1.2400 & -0.0031 & -2.1500^{* *} \mathrm{~s} \\ \text { Spomanag } & 0.7730 & 1.3100 & 0.9350 & 0.5600 & 0.7392 & 1.6700 \\ \text { F-Stastic } & 33.91 * * & & 47.36^{* *} & 27.14 * * \\ \text { Hausman } & 8.87 & & 14.74 & 9.65\end{array}$

test

Model REM REM REM REM

Notes:*indicates it ha passed test below level of $5 \% * *$ indicates it has passed test below level of $1 \%$.

The regression result indicates:

(1) Income level and consumption level of community resident has obscure effect on resources allocation efficiency of community sport, the regression analysis result is inconsistent with research assumption. The analysis thinks that the main cause of measurement result is inconsistent with assumption lies in that income level and consumption level of community residents are related to usage direction of community sport input.

(2) Regional economic development level has obscure effect on change of complete factor productivity, advancement rate of technology, change rate of technology efficiency, this conclusion is inconsistent with the above-mentioned assumption, which indicates that provinces with higher economic development level have higher ability in resources input of community sport, such as much more material and resources input, construction of organization resources, supply of information resources etc, but it has obscure effect on enhancement of resources allocation efficiency of community sport.

(3) Adjustment on resources allocation structure of mass sport has obvious effect on increasing resources allocation efficiency of community sport, while it has obscure effect on enhancement in technology efficiency and technology advancement index.

(4) Enforcement in sport awareness in community residents is helpful to increase resources allocation efficiency, technology efficiency and technology advancement index. Enforcement in sport awareness in community residents is helpful to increase population who usually participate in sport exercise, it is helpful for population participation increase in mass sport activity, it is helpful to increase body quality level of residents, so that it can promote enhancement in output in community sport resources.

(5) Education level has obscure effect on enhancement in resources allocation efficiency and technology efficiency in community sport, but it obscure effect on enhancement in technology advancement level. The regression analysis result is consistent with research and assumption in the original paper. Sport is the important part of education; enhancement in education level means the participation project in community sport activity has mastered true skills in body-building and formed better exercise habit etc, which is helpful for knowledge in sport education to produce effect.

(6) Population scale, jurisdiction area and the number of mass sport administrators have obscure effect on resources allocation of community sport. The number of mass sport organization has certain effect on increasing resources allocation efficiency of community sport; it has obscure effect on technology efficiency and technology advancement. Mass sport organization plays an inevitable role in activity development of community sport, except to organize community residents to participate in body-buidling; it can also promote community residents to form better exercise habit so that it further enhances the cohesive force of mass sport organization. In addition, it has promotion effect on enhancement in output level in commnity sport resources.

\section{Summary}

This paper adopts random effect model to make regression analysis on elements of affecting resources allocation efficiency of community sport. Resources allocation structure of mass sport, sport awareness of community residents, mass sport organization have obvious positive effect of increasing resources allocation efficiency of community sport, effect of regional economic development level on resources allocation efficiency of community sport is inconsistent with the 
original assumption, its main cause lies in that it has waste situation in the allocation process. Community resident awareness, education level has obvious effect on increasing index of technology advancement. Sport awareness of community residents has obvious effect on increasing technology efficiency of community sport resources allocation. Effect of Indexes such as consumption level of residents and regional economic development level, income level of residents, population scale and jurisdiction area, the number of community sport instructor etc on community sport allocation efficiency, technology efficiency and technology advancement has nor reached obvious level.

\section{References}

[1] Communique of The $5^{\text {th }}$ Plenary Conference of China Seventeenth CPC Central Committee.

Beijing : People's Publishing House, 2010, p25.

[2] Yuan Xiaoling. State and Countermeasure Research on Sport Public Facility in Zhijiang. Neijing Science and Technology, 2011, Vol 7, p28-29..

[3] Cui Dongxia, Wang Junling. Research on Sport Facility Resources Allocation in City Community of Zhengzhou. Journal of Henan Institute of Education (edition of social sciences)，2009，Vol 28(3), p52-59..

[4] Liang Huichao etc. Research on Resources Sharing Mechanism of School Sport Facility. Journal of Economic Management and Carder Institute of Jilin, 2010, Vol 24(4), p99-103.

[5] Liu Yujie, Zhang Qi. Discusison on Construction Channel of Public Service System of Chinese Sport [J].Commercial Culture, 2011, Vol 10.

[6] Chen Fei. Promote Reasonable Allocation of Public Education Resources in Rural Area. Journal of Yancheng Normal University（Humanities and Social Sciences Edition）,2011,Vol 29(1), p101-104.

[7] Cai Qin, Cao Jian. Education Equality: Reasonable Principle on Allocating Education Resources. Jiangsu Higher Education,2011,Vol 5, p23-26.

[8] Wang Xitang. Discussion and Research on Education Resources Application and Development of School Sport. Education Perspective,2011,Vol 1, p 132-135.. 